\title{
Biological and chemical investigation of Allium cepa L. response to selenium inorganic compounds
}

\author{
M. Michalska-Kacymirow • E. Kurek • A. Smolis • \\ M. Wierzbicka • E. Bulska
}

Received: 19 December 2013 /Revised: 27 February 2014 / Accepted: 3 March 2014 / Published online: 21 March 2014

(C) The Author(s) 2014. This article is published with open access at Springerlink.com

\begin{abstract}
The aim of this study was to evaluate the biological and chemical response of Allium cepa L. exposed to inorganic selenium compounds. Besides the investigation of the total content of selenium as well as its chemical speciation, the Allium test was used to evaluate the growth of onion roots and mitotic activity in the roots' meristem. The total content of selenium was determined by inductively coupled plasma mass spectrometry (ICP MS). High-performance liquid chromatography (HPLC), coupled to ICP MS, was used for the selenium chemical speciation. Results indicated that $A$. cepa plants are able to biotransform inorganic selenium compounds into their organic derivatives, e.g., Se-methylselenocysteine from the $\mathrm{Se}(\mathrm{IV})$ inorganic precursor. Although the differences in the biotransformation of selenium are due mainly to the oxidation state of selenium, the experiment has also shown a fine effect of counter ions $\left(\mathrm{H}^{+}, \mathrm{Na}^{+}, \mathrm{NH}_{4}^{+}\right)$on the response of plants and on the specific metabolism of selenium.
\end{abstract}

Keywords Speciation of selenium $\cdot$ Allium cepa $\cdot$ Hydroponic cultivation $\cdot$ Se-methylselenocysteine $\cdot$ Se-methionine $\cdot$ Allium test

Published in the topical collection Euroanalysis XVII (The European Conference on Analytical Chemistry) with guest editor Ewa Bulska.

M. Michalska-Kacymirow

College of Inter-Faculty Individual Studies in Natural Science and Mathematics, University of Warsaw, Żwirki i Wigury 93, 02-089 Warsaw, Poland

E. Kurek $\cdot$ E. Bulska $(\square)$

Faculty of Chemistry, Biological and Chemical Research Centre, University of Warsaw, Żwirki i Wigury 101, 02-089 Warsaw, Poland

e-mail: ebulska@chem.uw.edu.pl

A. Smolis $\cdot$ M. Wierzbicka

Faculty of Biology, University of Warsaw,

Miecznikowa 1, 02-096 Warsaw, Poland

\section{Introduction}

Selenium is an essential element for the proper functioning of humans and animals. Anticancer properties of selenium are of particular interest. Although the mechanisms of its activities are not fully understood, a clear correlation between the increased morbidity of cancer and the deficiencies of selenium in the diet was noted [1,2]. Several investigations on populations from selenium-poor areas give statistically proven evidence that the selenium deficit increases cancer appearance, when compared to the areas rich in this element [3]. Therefore, all researches towards the development of dietary supplementation of selenium, which could compensate a natural deficiency of selenium in the human diet, are considered to be important.

It is expected that the consumption of vegetables, which have the ability to biotransform selenium inorganic forms into its organic derivatives-selenoaminoacids (e.g., Semethylselenocysteine), which are most beneficial for humans, may play an important role in the prevention of cancer. Several studies were focused on vegetables from the Allium group, e.g., garlic, onion, and leek, which have the ability to take up large amounts of selenium [4-8]. Major selenium chemical species found in these selenized plants are Semethylselenocysteine and its derivatives such as $\gamma$-glutamylSe-methylselenocysteine, which are known to be the most effective selenium inhibitors of tumor formation.

It was already found that the biotransformation of selenium in plants depends on the oxidation state of selenium in its inorganic precursors [4-6]. The aim of this study was to evaluate the specific biological response of Allium cepa L. plants grown hydroponically. Therefore, besides the investigation of the total content of selenium as well as its chemical speciation, the Allium test was used to evaluate the growth of onion roots and the mitotic activity in the roots' meristem [8]. 


\section{Experimental}

Instrumentation

Inductively coupled plasma mass spectrometry An ELAN 6100 DRC inductively coupled plasma mass spectrometer (ICP MS) (PerkinElmer SCIEX, USA) was used. A conventional Mainhardt nebulizer and a quartz cyclonic spray chamber were used for sample introduction. The ICP MS conditions were as follows: plasma power $1,100 \mathrm{~W}$, plasma argon flow $15 \mathrm{~L} / \mathrm{min}$, auxiliary flow $1.21 \mathrm{~L} / \mathrm{min}$, and nebulizer flow $0.86 \mathrm{~L} / \mathrm{min}$. The interference-free isotope ${ }^{82} \mathrm{Se}$ was monitored.

High-performance liquid chromatography An Agilent 1200 (Agilent, USA) high-performance liquid chromatograph (HPLC) equipped with a Hamilton PRP-X100 anion exchange column, $250 \mathrm{~mm} \times 4.6 \mathrm{~mm}$ i.d. and $10 \mu \mathrm{m}$ (Hamilton, USA), was used in connection with ICP MS. The HPLC column was connected to the nebulizer of the ICP MS by a color-coded PEEK tubing (orange 1/16", 0.020"; maximum pressure 5,000 psig; volume $100 \mu \mathrm{L}$ ).

Chemicals and standards

All chemicals were of analytical grade and were used without further purification. Nitric acid (V) $65 \%$, hydrochloric acid $37 \%$, internal standard (yttrium), and multielemental ICP MS standard solutions were obtained from Merck (Merck, Germany). Water for the analysis was obtained from the Milli-Q System (Millipore, USA).

Sodium selenite $\left(\mathrm{Na}_{2} \mathrm{SeO}_{3}\right)$, sodium hydrogen selenite $\left(\mathrm{NaHSeO}_{3}\right)$, sodium selenate $\left(\mathrm{Na}_{2} \mathrm{SeO}_{4}\right)$, and sodiumammonium selenate $\left(\mathrm{NaNH}_{4} \mathrm{SeO}_{4}\right)$ were obtained from Sigma, Germany. Selenomethionine (SeMet) and selenomethylselenocysteine (SeMetSeCys) were purchased from Sigma (USA). L- $\gamma$-Glutamyl-Se-methylseleno-L-cysteine ( $\gamma$-glutamyl-SeMetSeCys) was obtained from PharmaSe Inc. (USA). Selenomethionine-Se-oxide (SeMetO) was achieved by adding an excess of oxidizing agent, $1 \mathrm{~mL}$ of $30 \%(v / v) \mathrm{H}_{2} \mathrm{O}_{2}$, to a $10-\mathrm{mL}$ aliquot of a $0.1 \mathrm{~mol} / \mathrm{L} \mathrm{HCI}$ solution of selenomethionine ( $1 \mathrm{mg} \mathrm{Se} / \mathrm{L})$ and left overnight in the dark. Chemicals used for Knop's medium, $\mathrm{Ca}\left(\mathrm{NO}_{3}\right)$, $\mathrm{KNO}_{3}, \mathrm{KH}_{2} \mathrm{PO}_{4}, \mathrm{KCl}, \mathrm{MgSO}_{4}$, EDTA-Fe, were obtained from $\mathrm{POCH}$ (Poland).

The reference material BCR-402, white clover, with a certified total selenium content of $6.70 \pm 0.25 \mu \mathrm{g} / \mathrm{g}$, was obtained from the European Commission Joint Research Centre, Institute for Reference Materials and Measurements, Belgium.

Plant cultivation

A. cepa L. plants were cultivated in 330-mL Erlenmeyer flasks at room temperature. After preincubation $(24 \mathrm{~h}$ in distilled water, then $24 \mathrm{~h}$ in Knop's medium), plants were transferred to Knop's medium (control plants) or to Knop's medium supplemented with selenium inorganic salts (test plants). The following selenium compounds were used: (i) anhydrous sodium selenite, (ii) sodium hydrogen selenite, and two $\mathrm{Se}(\mathrm{VI})$ salts: (iii) sodium selenate and (iv) sodium-ammonium selenate, all prepared up to the content of selenium of $10 \mathrm{mg} / \mathrm{L}$. All solutions supplemented with selenium inorganic salts were replaced on a daily basis to assure a constant concentration of selenium during the cultivation period.

\section{Growth experiments}

The length of roots and root growth rate (RGR) were inspected at the first day, than after 1, 2, 4, and 5 days of culture. The entire biomass was evaluated after 5 days of culture, by determining the fresh weight (FW) and dry weight (DW) of aerial and underground tissues. Note: for the DW, roots, leaves, and bulbs were dried at $30{ }^{\circ} \mathrm{C}$ for $72 \mathrm{~h}$.

\section{Allium test}

Allium tests were performed by cutting $2 \mathrm{~mm}$ of the root tips of each onion after 12, 24, 48, 72, and $96 \mathrm{~h}$ of cultivation; always, five root tips from each individual were used. They were macerated and stained in aceto-orcein $(2 \%$ orcein in $45 \%$ acetic acid) for $24 \mathrm{~h}$ at room temperature. Two root tips were then squashed on each slide.

The mitotic activity in root tips was inspected under a light microscope, in the bright field. A mitotic index (number of dividing cells in 1,000 meristem cells) was counted for each slide.

\section{Chemical investigation}

\section{Determination of selenium}

In order to determine the total content of selenium, approximately $0.1 \mathrm{~g}$ of plant tissue was digested in $8 \mathrm{~mL}$ of $\mathrm{HNO}_{3}$ (65\%) under the following conditions: (i) $500 \mathrm{~W} / 10 \mathrm{~min}$, (ii) $1,000 \mathrm{~W} / 15 \mathrm{~min}$, and (iii) cooling/5 min. A microwaveassisted unit (Anton Paar Multiwave Sample Preparation System, Austria) with Teflon vessels was used. Digested samples were filtered through sterile syringe-driven $0.45-\mu \mathrm{m}$ nylon membrane filters (Millex, France). Transparent solutions were transferred to plastic tubes, filled with deionized water to $20 \mathrm{~mL}$, and stored in a refrigerator below $4{ }^{\circ} \mathrm{C}$ before measurements.

Calibration was performed with the standard solutions containing 1,10 , and $100 \mu \mathrm{g} / \mathrm{L}$ of selenium, and yttrium $(10 \mu \mathrm{g} / \mathrm{L})$ was used as an internal standard for instrument drift correction. The total measurement time was $25 \mathrm{~s}$. 
The validation of the analytical procedure was performed with certified reference material BCR-402, white clover, with total selenium content of $6.70 \pm 0.25 \mu \mathrm{g} / \mathrm{g}$ and which was digested in the same conditions as described above. The obtained result of $6.74 \pm 0.68 \mu \mathrm{g} / \mathrm{g}$ was considered as being within the uncertainty of the certified value.

\section{Extraction procedure}

After 5 days of cultivation, all control and test plants were thoroughly cleaned under running tap water and subsequently rinsed with distilled water. Wet roots were weighted and then dried at $30^{\circ} \mathrm{C}$ for $72 \mathrm{~h}$. About $0.1 \mathrm{~g}$ of dry mass was weighted in the plastic centrifuge tubes; then, $1 \mathrm{~mL}$ of water was added. The extraction supported by ultrasonic shaking $\left(30^{\circ} \mathrm{C}\right.$ for $30 \mathrm{~min}$ ) was performed with water. The supernatant was then separated from the residue by centrifugation for $15 \mathrm{~min}$ at $13,000 \mathrm{rpm}$ and filtered through $0.45-\mu \mathrm{m}$ membrane filters. Aliquots used for HPLC separation were kept at $-10{ }^{\circ} \mathrm{C}$ before measurements.

\section{Chromatographic separation procedure}

The conditions for HPLC chromatographic separation were as follows. Eluent A, $5 \mathrm{mM}$ acetate buffer ( $\mathrm{pH}$ 4.7), and eluent B, $150 \mathrm{mM}$ acetate buffer ( $\mathrm{pH} 4.7)$, were used. The mobile phase was delivered at $1.0 \mathrm{~mL} / \mathrm{min}$ in gradient mode: $0-4 \mathrm{~min}-$ $100 \% \mathrm{~A}, 4-7 \mathrm{~min}$ - from $100 \% \mathrm{~A}$ to $0 \% \mathrm{~A}$, and 7-30 min$100 \% \mathrm{~B}$. The conditions for HPLC chromatographic separation were optimized for the needs of the experiment. Filtered solutions were degassed before the injection; then, $100 \mu \mathrm{L}$ of the sample was injected for HPLC ICP MS measurements.

The standard solutions were prepared to obtain the concentration of $500 \mu \mathrm{g} / \mathrm{L}$ of selenium. Retention times were $\mathrm{SeMetO}=2.2 \mathrm{~min}$, SeMetSeCys=2.8 $\mathrm{min}$, SeMet=5.0 min, $\mathrm{Se}(\mathrm{IV})=9.8 \mathrm{~min}, \gamma$-glutamyl-SeMetSeCys $=13.0 \mathrm{~min}$, and $\mathrm{Se}(\mathrm{VI})=15.0 \mathrm{~min}$.

\section{Results and discussion}

\section{Plant growth}

The growth of roots was examined visually for control and test plants within 5 days. The roots of plants cultivated in the presence of $\mathrm{Se}(\mathrm{IV})$ compounds $\left(\mathrm{Na}_{2} \mathrm{SeO}_{3}\right.$ or $\left.\mathrm{NaHSeO}_{3}\right)$ were significantly shorter compared to those treated with $\mathrm{Se}(\mathrm{VI})$ compounds $\left(\mathrm{Na}_{2} \mathrm{SeO}_{4} \cdot 10 \mathrm{H}_{2} \mathrm{O}\right.$ or $\left.\mathrm{NaNH}_{4} \mathrm{SeO}_{4}\right)$. After $96 \mathrm{~h}$, the average increment of onion roots cultivated in the presence of sodium selenite, hydrogen sodium selenite, sodium selenate, and sodium-ammonium selenate was, respectively, 2.0, $1.3,4.1$, and $4.2 \mathrm{~cm}$. As it was expected, the highest growth rate was found for the control plants $(6.2 \mathrm{~cm})$.
Clearly, all inorganic compounds inhibit root growth, and the most pronounced inhibition effects were observed in the presence of $\mathrm{Se}(\mathrm{IV})$, with a less pronounced but still significant difference between sodium selenite and sodium hydrogen selenite. The presence of Se(VI) does not depend significantly on the type of counter ion.

The effect of selenium on the growth of roots was also supported by evaluating the amount of biomass (after $96 \mathrm{~h}$ ). The weight of the fresh roots of plants exposed to Se(IV) or $\mathrm{Se}(\mathrm{VI})$ was 52 or $67 \%$, respectively, of that of the control plant.

\section{Mitotic activity}

The evaluation of the mitotic activity of root tips was performed for $\mathrm{Na}_{2} \mathrm{SeO}_{3}$ and $\mathrm{Na}_{2} \mathrm{SeO}_{4}$. The biological responses of the root cells are shown in Fig. 1a-c. Interestingly, the mitotic activity of root tips was not reduced in the presence of $\mathrm{Na}_{2} \mathrm{SeO}_{4}$ (Fig. 1a, c); however, the significant reduction of the number of divisions was observed in the presence of $\mathrm{Se}(\mathrm{IV})$ (Fig. 1b). Although both inorganic selenium compounds decreased the growth of roots, in the case of $\mathrm{Na}_{2} \mathrm{SeO}_{3}$, the inhibitory effect was expressed also in the mitotic divisions, resulting in a reduction of the mitotic index (Fig. 2).

\section{Uptake of selenium by roots}

The total content of selenium in the onion roots depends on its chemical form. The results indicate that the process of its uptake varies between $\mathrm{Se}(\mathrm{IV})$ and $\mathrm{Se}(\mathrm{VI})$ compounds. The average content of selenium in roots grown in the presence of various inorganic selenium compounds is listed in Table 1. Although Se(IV) affects the plants significantly stronger than $\mathrm{Se}(\mathrm{VI})$ compounds, its uptake efficiency is almost three times lower. The uptake efficiency depends significantly on the selenium oxidation stage rate; moreover, it was also associated with the type of salt, specifically the counter ions, for both $\mathrm{Se}(\mathrm{IV})$ and $\mathrm{Se}(\mathrm{VI})$ species.

\section{Selenium speciation}

In order to evaluate selenium chemical speciation, roots of three individual plants from each of the test culture were collected. Thus, five sets of plants were examined: (i) control plants and those exposed to (ii) sodium selenite, (iii) sodium hydrogen selenite, (iv) sodium selenate, and (v) sodiumammonium selenate. The following standard compounds were used for the calibration of the retention time of chromatographic separation: SeMetO (2.2 min), SeMetSeCys $(2.8 \mathrm{~min})$, SeMet $(5.0 \mathrm{~min}), \mathrm{Se}(\mathrm{IV})(9.8 \mathrm{~min}), \gamma$-glutamylSeMetSeCys (13.0 min), and Se(VI) $(15.0 \mathrm{~min})$. On the basis of the retention time, the presence of those compounds in the extracts from plant tissues was identified. 

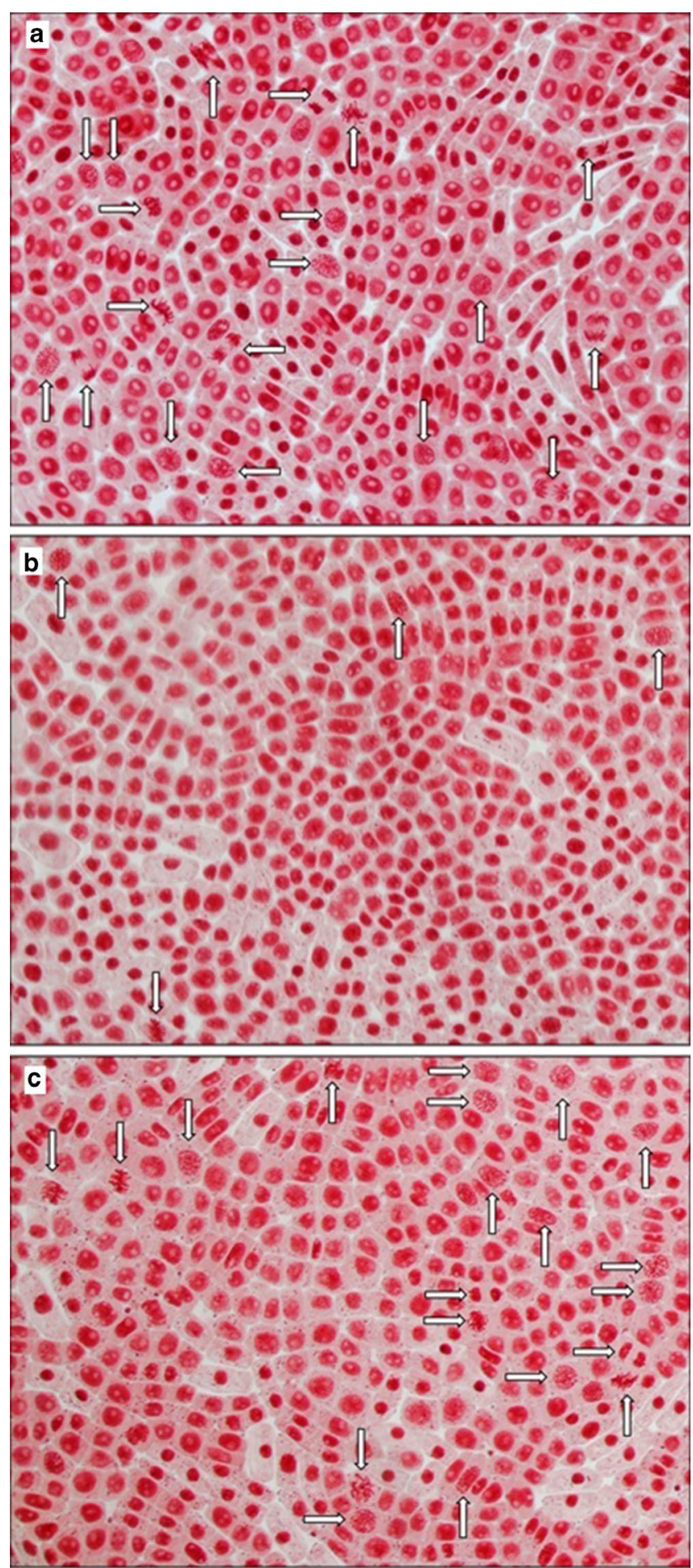

Fig. 1 Mitotic divisions (white arrows) of meristematic plant cells in Allium cepa L. grown in Knop's medium: a no additives, b with $\mathrm{Se}(\mathrm{IV})$, and $\mathbf{c}$ with $\mathrm{Se}(\mathrm{VI})$. Magnification $\times 400$

In plants treated with $\mathrm{Se}(\mathrm{VI})$, the presence of only one original form of selenium was revealed (Fig. 3c, d). In the case of plants treated with $\mathrm{Se}(\mathrm{IV})$, all above-listed selenium species (standard compounds) were identified. Two signals at $R_{\mathrm{t}}=10.4$ min and $R_{\mathrm{t}}=18.6$ min were not identified due to the

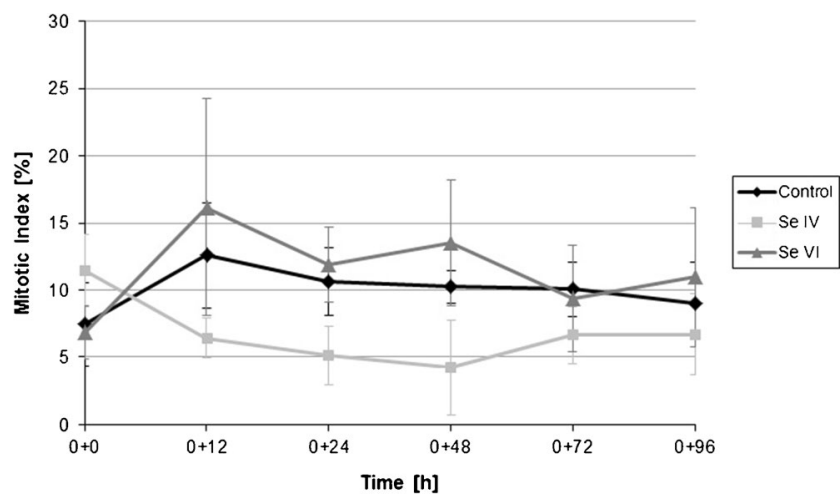

Fig. 2 Mitotic index (expressed as a percentage of dividing cells) for root tips of Allium cepa L. Diamonds control plants; squares and triangles plants cultivated in Knop's medium enriched with sodium selenite (IV) and sodium selenate (VI), respectively. The concentration of selenium was constantly $10 \mathrm{mg} / \mathrm{L}$

lack of respective standard compounds (Fig. 3a, b). Thus, the ability of A. cepa L. plants to metabolize inorganic species of $\mathrm{Se}(\mathrm{IV})$ to its organic derivatives was confirmed $[4,5]$. A similar effect of the metabolism of inorganic precursors of selenium was observed also for other plants, e.g., Allium schoenoprasum [6].

The detailed examination of the chromatograms, especially Fig. 3a, b, allows also the detection of the different responses due to the counter ions at $\mathrm{Se}(\mathrm{IV})$ compounds. The effect was most pronounced in the case of abundant species, SeMetSeCys. The content of selenium in the fractions of SeMetSeCys was 201 and $107 \mathrm{mg} / \mathrm{kg}$ when onion roots were grown in the presence of $\mathrm{NaHSeO}_{3}$ and $\mathrm{Na}_{2} \mathrm{SeO}_{3}$, respectively. This is in line with the data on the efficiency of uptake of selenium (Table 1). The contrary effect was noticed for Se(VI); the signal recorded at $15.0 \mathrm{~min}$ was more than two times higher for the plant exposed to sodium selenite compared to that for the plant exposed to sodium hydrogen selenite $(16 \mathrm{mg} / \mathrm{kg})$. These results indicate that the biotransformation of selenium depends not only on the oxidation state of selenium, but also on the counter ions. The presence of $\mathrm{NaHSeO}_{3}$ not only supports the efficiency of the uptake of selenium, but also promotes the biotransformation of the inorganic precursor to its organic derivatives, mainly SeMetSeCys.

Table 1 The content of selenium in roots (dry mass) grown in the presence of selected selenium compounds

Compound

Total content $\mathrm{t}^{\mathrm{a}}[\mathrm{mg} / \mathrm{kg}]$

$\mathrm{Na}_{2} \mathrm{SeO}_{3}$

$670 \pm 15$

$\mathrm{NaHSeO}_{3}$

$979 \pm 15$

$\mathrm{Na}_{2} \mathrm{SeO}_{4} \cdot 10 \mathrm{H}_{2} \mathrm{O}$

$2,700 \pm 25$

$\mathrm{NaNH}_{4} \mathrm{SeO}_{4}$

$2,100 \pm 20$

${ }^{\mathrm{a}}$ The value \pm expanded uncertainty $(k=2)$ for the measurements 

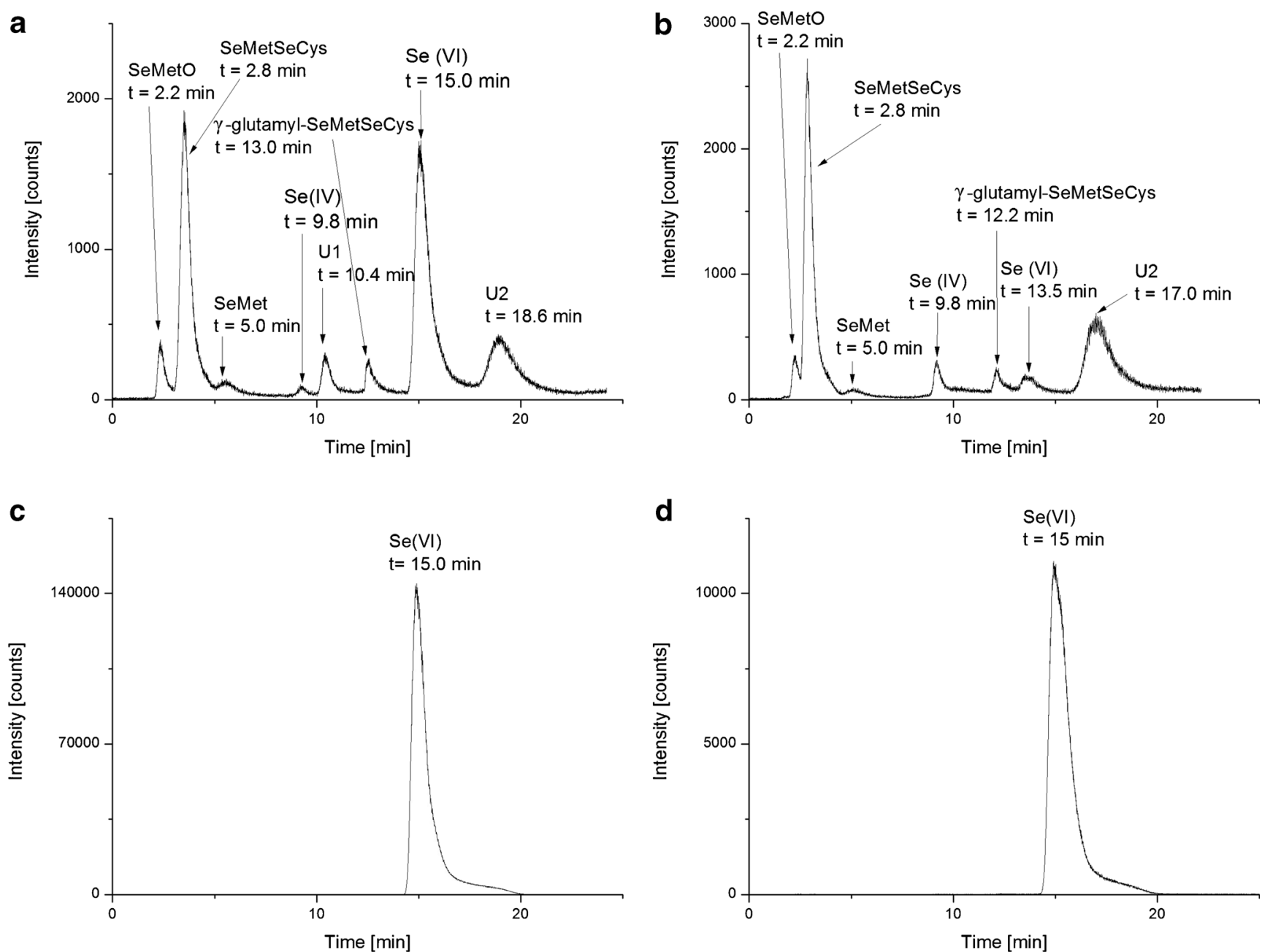

Fig. 3 Chromatograms obtained from the extracts of the roots of plants grown in Knop's medium enriched with $\mathbf{a} \mathrm{Na}_{2} \mathrm{SeO}_{3}, \mathbf{b} \mathrm{NaHSeO}_{3}, \mathbf{c ~} \mathrm{Na}_{2} \mathrm{SeO}_{4}$, and $\mathbf{d ~} \mathrm{NaNH}_{4} \mathrm{SeO}_{4}$

\section{Conclusions}

In this work, biological and chemical methods were applied in order to obtain complementary information on the plants' (A. серa $\mathrm{L}$.) response to the different inorganic salts of selenium $\left(\mathrm{NaSeO}_{3}, \mathrm{NaHSeO}_{3}, \mathrm{Na}_{2} \mathrm{SeO}_{4}, \mathrm{NaNH}_{4} \mathrm{SeO}_{4}\right)$. A significant influence of the oxidation state of selenium on its metabolism in plants as well as on the mitotic activity in the roots' meristem has been confirmed. The use of the Allium test as well as observing the growth of the biomass of the onion roots enabled the evaluation of the response of A. сера on the presence of various inorganic selenium compounds and the demonstration of the effect of counter ions $\left(\mathrm{H}^{+}, \mathrm{Na}^{+}, \mathrm{NH}_{4}^{+}\right)$, most pronounced in the case of Se(IV) compounds.

Acknowledgments M. Michalska-Kacymirow's research was partially supported by the EU through the European Social Fund, contract number UDA-POKL.04.01.01-00-072/09-00. E. Bulska and E. Kurek acknowledge the financial support by project 2012/05/B/ST4/01219 financed by the National Science Centre (NCN) in Poland. Part of the study was carried out at the Biological and Chemical Research Centre, University of Warsaw, established within the project cofinanced by the European Union from the European Regional Development Fund under the Operational Programme Innovative Economy, 2007-2013.

Open Access This article is distributed under the terms of the Creative Commons Attribution License which permits any use, distribution, and reproduction in any medium, provided the original author(s) and the source are credited.

\section{References}

1. Brinkman M, Reulen RC, Kellen E, Buntinx F, Zeegers MP (2006) Are men with low selenium levels at increased risk of prostate cancer? Eur J Cancer 42:2463-2471

2. Fritz H, Kennedy D, Fergusson D, Fernandes R, Cooley K, Seely A, Sagar S, Wong R, Seely D (2011) Selenium and lung cancer: a systematic review and meta analysis. PLoS ONE 6(11):e26259 
3. Fernandez-Banares F, Cabre E, Esteve M, Abad-Lacruz P, Lachica M, Gil A, Gassull M (2002) Serum selenium and risk of large size colorectal adenomas in a geographical area with a low selenium status. Am J Gastroenterol 97(2103-2):108

4. Wróbel K, Wróbel K, Kannamkumarath S, Caruso J, Wysocka IA, Bulska E, Świątek J, Wierzbicka M (2004) HPLC-ICP-MS speciation of selenium in enriched onion leaves - a potential dietary source of Semethylselenocysteine. Food Chem 86:617-623

5. Bulska E, Wysocka IA, Wierzbicka MH, Proost K, Janssens K, Falkenberg G (2006) In vivo investigation of the distribution and the local speciation of selenium in Allium cepa L. by means of microscopic X-ray absorption near-edge structure spectroscopy and confocal microscopic X-ray fluorescence analysis. Anal Chem 78: 7616-24

6. Kápolna E, Shah M, Caruso J, Fodor P (2007) Selenium speciation studies in Se-enriched chives (Allium schoenoprasum) by HPLC-ICPMS. Food Chem 101:1398-1406

7. Larsen EH, Lobinski R, Burger-Meÿer K, Hansen M, Ruzik R, Mazurowska L, Rasmussen PH, Sloth JJ, Scholten O, Kik C (2006) Uptake and speciation of selenium in garlic cultivated in soil amended with symbiotic fungi (mycorrhiza) and selenate. Anal Bioanal Chem 385:1098-108

8. Wierzbicka M, Antosiewicz D (1988) Allium test—some questions. Acta Soc Bot Pol 57:201-215 